\title{
Differential Signaling and Hypertrophic Responses in Cyclically Stretched vs Endothelin-1 Stimulated Neonatal Rat Cardiomyocytes
}

\author{
Henriëtte W. de Jonge, ${ }^{1,4}$ Dick H.W. Dekkers, ${ }^{1}$ Adriaan B. Houtsmuller, ${ }^{2}$ \\ Hari S. Sharma, ${ }^{3}$ and Jos M. J. Lamers, ${ }^{1, *}$ \\ ${ }^{1}$ Departments of Biochemistry and ${ }^{3}$ Pharmacology, Cardiovascular Research School COEUR and \\ ${ }^{2}$ Pathological Anatomy, Erasmus MC, University Medical Center, Rotterdam, The Netherlands; \\ ${ }^{4}$ Division of Veterinary Anatomy and Physiology, Department of Pathobiology, School of Veterinary Medicine, \\ University of Utrecht, P.O. Box 80.158, 3508TD Utrecht, The Netherlands (present affiliation)
}

\begin{abstract}
Numerous neurohumoral factors such as endothelin (ET)-1 and angiotensin (Ang) II as well as the stretch stimulus act concertedly in the in vivo overloaded heart in inducing hypertrophy and failure. The primary culture of rat neonatal cardiomyocytes is the only in vitro model that allows the comparative analysis of growth responses and signaling events in response to different stimuli. In the present study, we examined stretched rat cardiomyocytes grown on flexible bottomed culture plates for hypertrophic growth responses (protein synthesis, protein/DNA ratio, and cell volume), F-actin filaments rearrangement (by confocal laser scanning microscopy), and for signaling events (activation of phospholipase $C$ [PLC]- $\beta$, protein kinase $C$ [PKC], mitogenactivated protein [MAP] kinases) and compared these responses with ET-1 (10-8 M)-stimulated cells. Cyclic stretch for $48 \mathrm{~h}$ induced hypertrophic growth in cardiomyocytes indicated by increases in the rate of protein synthesis, cell volume, and diameter, which were less pronounced in comparison to stimulation by ET-1. During cyclic stretch, we observed disoriented F-actin, particularly stress-fibers whereas during ET-1 stimulation, Factins rearranged clearly in alignment with sarcomeres and fibers. The upstream part of signaling by cyclic stretch did not follow the PLC $\beta$-PKC cascade, which, in contrast, was strongly activated during ET- 1 stimulation. Cyclic stretch and, to greater extent, ET-1 stimulated downstream signaling through ERK, p38 MAP kinase, and JNK pathways, but the involvement of tyrosine kinase and PI3 kinase-Akt signaling during cyclic stretch could not be proven. Taken together, our results demonstrate that both cyclic stretch and ET-1 induce hypertrophic responses in cardiomyocytes with different effects on organization of F-actin stress fibers in case of stretch. Furthermore, on the short-term basis, cyclical stretch, unlike ET-1, mediates its hypertrophic response not through activation of PLC- $\beta$ and PKC but more likely through integrin-linked pathways, which both lead to downstream activation of the MAP kinase family.
\end{abstract}

Index Entries: Cardiomyocytes; cyclic stretch; endothelin-1; hypertrophy; signal transduction; confocal scanning laser microscopy.

\section{INTRODUCTION}

When the heart is exposed in vivo to chronically increased workload, it responds by hypertrophic growth and altered gene expression. These processes subsequently lead to the enlargement and an altered

\footnotetext{
${ }^{*}$ Author to whom all correspondence and reprint requests should be addressed. E-mail:j.lamers@erasmusmc.nl
}

phenotype of the ventricle(s) mainly as a result of increase in myocyte cell size in absence of cell division, ultimately inducing heart failure. It has been fairly well established that many neurohumoral factors such as endothelin (ET)-1, angiotensin (Ang) II, $\alpha$-adrenergic agonists, cardiotrophin (CT)-1, leukemic inhibitory factor (LIF), and several growth factors (insulin-like growth factor [IGF]-1, transforming growth factor $[\mathrm{TGF}]-\beta$, etc.), as well as mechanical 
stimuli, act concertedly in inducing myocardial hypertrophy and failure. Because of the various cell types other than myocytes present in myocardium and the multiple neural, humoral, and mechanical factors involved in hypertrophic growth and phenotypic changes, the differential analysis of the various intracellular signal transduction pathways in vivo is virtually impossible. Therefore, up to now, knowledge about the signaling events is based on results obtained in the model of rat neonatal cardiomyocytes. Using the latter model, the effects of the neurohumoral, cytokine, or growth factors, but also mechanical stretch, can be studied separately.

G protein-receptor agonists including ET-1, phenylephrine, and angiotensin II induce in vitro a form of hypertrophy comparable to that observed in vivo during pressure overload, with cardiomyocytes exhibiting an increased diameter due to the addition of new sarcomeres in parallel (2-4). In contrast, interleukin-6 family cytokines such as LIF and CT-1 act through the transmembrane gp130 protein to induce cardiac hypertrophy resembling the phenotype produced during volume overload with increased cardiomyocyte length due to the addition of sarcomeres in series $(4,5)$. As to exposure to mechanical stretch, the nature of the induced signaling processes will be dependent on the direction of the force (uni-axial or circular), the frequency (static or cyclic), and the duration of exposure to stretch. Most investigators who have studied the responses of rat neonatal cardiomyocytes to mechanical stretch have applied short-term static uni-axial strain $(6,7)$. In this situation, like the stimulation by mediators such as ET-1, numerous intracellular signaling pathways via phospholipase C (PLC) $-\beta,-D$, and $-A_{2}$ followed by activation of the kinase cascades such as protein kinase $C$ (PKC), the tyrosine kinases, mitogen-activated protein (MAP) kinases and activators, c-Jun N-terminal protein kinases (JNK), 90-kDa S6 kinase, and the Janus kinase (JAK)/ signal transducers and activators of transcription (STAT) pathway have been shown to be involved in the development of hypertrophy and change of phenotype $(6,8,9)$. However, because in vivo, the intact heart contracts rhythmically and can become chronically overloaded by increased pressure or volume, long-term cyclic and circular stretching of cultured cardiomyocytes may better mimic the in vivo situation than static uni-axial stretch. In this regard, Carver and colleagues have shown that cyclically, rather than statically, stretched fibroblasts produce type III collagen, resulting in increased ratio of collagen type III to type I as also observed in vivo at the onset of myocardial hypertrophic growth (10).

In the present study, we applied long-term rhythmic (cyclic) and circular stretch to the model of rat neonatal cardiomyocytes. We examined comparatively the initial signaling events and the long-term hypertrophic growth responses after cyclic stretch- and ET-1-mediated stimulation. Short-term signaling responses were studied by analyzing the activation of PLC- $\beta$, PKC, and MAP kinase family. Long-term responses were studied by analysis of hypertrophic parameters such as rate of protein synthesis, protein/DNA ratio, rearrangements of F-actin filaments, and changes in cell volume and diameter. The possible involvement of phosphoinositide (PI)-3 kinaseAkt and protein-tyrosine phosphorylation was evaluated by measuring the effects of blockers of these pathways, Wortmannin and Genistein respectively, on hypertrophic growth of cardiomyocytes. Whether ET-1 is involved in the effects of cyclic stretch or hypertrophic growth of cardiomyocytes due to paracrine and/or autocrine mechanisms was examined by employing $\mathrm{ET}_{\mathrm{A}}, \mathrm{AT} 1$, and AT2 receptor blockers during stretch.

\section{MATERIALS AND METHODS}

The investigations conform to the Guide for Care and Use of Laboratory Animals published by the US National Institutes of Health (NIH Publication No. 8523, revised 1996).

\section{Cell Culture Reagents}

Flexible bottom culture plates, collagen type Icoated, were purchased from Flexcell International Corp. (Hillsborough, NC), four-well culture plates were purchased from Becton Dickinson (Plymouth, England), Dulbecco's modified Eagle's medium (DMEM) and M199 were purchased from GibcoBRL (Life Technologies, Scotland, UK), fetal sera was purchased from Boehringer Mannheim (Germany), and horse sera was purchased from Sigma Aldrich, FX2000 Flexercell Strain Unit System from Flexcell International Corp. (Hillsborough, NC).

\section{Radioactive Chemicals}

$\mathrm{L}-\left[4,5-{ }^{3} \mathrm{H}\right]$-Leucine and myo- $\left[2-{ }^{3} \mathrm{H}\right]$-inositol were purchased from Amersham International plc (Buckinghamshire, UK), ${ }^{125}$ I-labeled goat anti-mouse immunoglobulin (Ig) $G, F\left(a b^{\prime}\right)_{2}$ fragment was purchased from from ICN Pharmaceuticals, Inc. (CA), ${ }^{125}$ I-labeled donkey anti-rabbit IgG, $\mathrm{F}\left(\mathrm{ab}^{\prime}\right)_{2}$ fragment was purchased from Amersham International plc (Buckinghamshire, UK).

\section{Antibodies and Fluorescent Ligands}

Phospho-specific p38 MAP kinase (Thr180/Thr182) rabbit polyclonal antibody and phospho-p44/42 MAP kinase (Thr202/Thr204) rabbit polyclonal antibody 
were obtained from New England Biolabs, Inc. (Beverly, MA). Phospho-JNK mouse monoclonal IgG1, nPKC- $\varepsilon$ rabbit polyclonal $\mathrm{IgG}$, and $\mathrm{cPKC}-\alpha$ rabbit polyclonal IgG were obtained from Santa Cruz Biotechnology, Inc. (Santa Cruz, CA). TRITC-labeled goat anti-mouse IgG $(\mathrm{H}+\mathrm{L})$, fluorescen isothiocyanate (FITC)-Streptavidin, and biotinylated-goat anti rabbit IgG $(\mathrm{H}+\mathrm{L})$ were purchased from ZYMED Laboratories, Inc. (San Francisco, CA), and biotinylated anti-mouse IgG was purchased from Amersham. Phalloidin-FITC was from SigmaAldrich Chemie BV (Zwijndrecht, The Netherlands). Vectashield ${ }^{\circledR}$ Mounting Medium (H-1000) was obtained from Vector Laboratories, Inc. (Burlingame, CA)

\section{Experimental Procedures}

\section{Isolation and Culturing of Myocardial Cells}

Rat neonatal ventricular cardiomyocytes were isolated as described previously (11). Briefly, after preplating, cardiomyocytes were cultured on rigid- or flexible-bottom culture plates, collagen type I-coated, from Flexcell International Corp. (either $1.5 \times 10^{5}$ cells $/ \mathrm{cm}^{2}$ or $0.375 \times$ $10^{5}$ cells $/ \mathrm{cm}^{2}$, the latter density was chosen when cells had to be analyzed by confocal microscopy) up to $24 \mathrm{~h}$ in HEPES-buffered DMEM/M199 (4:1) supplemented with $5 \%$ fetal calf serum (FCS) and 5\% horse serum (HS), $100 \mathrm{U}$ penicillin $/ \mathrm{mL}$ and $100 \mu \mathrm{g}$ streptomycin $/ \mathrm{mL}$. Hereafter, the medium was changed in DMEM/M199 (4:1) with only $4 \% \mathrm{HS}$. After $64 \mathrm{~h}$, the medium was changed into serum-free DMEM/M199. Cells were grown in a 5\% $\mathrm{CO}_{2}$ incubator at $37^{\circ} \mathrm{C}$.

\section{Cyclic Stretch Protocol}

Five days after isolation, the six-well plates were placed on a Flexcell Strain Unit and the protocol of the applied cyclic stretch (30 cycles/min) was executed as described before (12). The protocol started out with a warming up period of 5\% elongation increasing 5\% every 15 min up to maximal 20\% elongation after $45 \mathrm{~min}$. In this way, the cardiomyocytes were exposed to cyclic stretch up to 24 or $48 \mathrm{~h}$. Control cells, also either grown on flexible-bottom or rigid-bottom culture plates were incubated for 24 or $48 \mathrm{~h}$ with or without ET-1 $\left(10^{-8} \mathrm{M}\right.$ final concentration). When the effects of tyrosine kinase inhibitor Genistein $(50 \mu M)$ or PI-3 kinase inhibitor Wortmannin $(1 \mu M)$ were tested, these inhibitors were added $2 \mathrm{~h}$ prior to the start of the stretch protocol. To test the paracrine or autocrine effects of ET- 1 or Ang $1 \mu \mathrm{M}$, the receptor blockers BQ123 $\left(\mathrm{ET}_{\mathrm{A}}\right)$ or $1 \mu M$ Dup 754 (AT1) and/or $1 \mu M$ PD123319 (AT2) were added $30 \mathrm{~min}$ before the start of the stretch protocol.

\section{MTT-AssAY}

To analyze the cell viability after stretch, a 3-[4,5 dimethylthiazol-2-yl]-2,5-diphenyl tetrazolium bro- mide (MTT) assay was performed as described by Hansen et al. (13). Briefly, cells were incubated with MTT $(1 \mathrm{mg} / \mathrm{mL})$ for $2 \mathrm{~h}$ at $37^{\circ} \mathrm{C}$ in a $\mathrm{CO}_{2}$ incubator, and after addition of extraction buffer $(20 \%$ sodium dodecyl sulfate [SDS] in 50\% $\mathrm{N}, \mathrm{N}$-dimethyl formamide, $\mathrm{pH} 4.7$ ) the optical density (OD) was measured.

\section{Cell Count}

To test whether experimental procedures caused cell loss from the culture plates, we counted cells before and after $24 \mathrm{~h}$ of stretch. Cells were detached from the culture plates by trypsinisation $(0.02 \%$ trypsine, $0.05 \%$ EDTA dissolved in $140 \mathrm{mM} \mathrm{NaCl}, 2.6 \mathrm{mM} \mathrm{KCl}, 1.04 \mathrm{mM}$ $\mathrm{KH}_{2} \mathrm{PO}_{4}, 8.1 \mathrm{mM} \mathrm{Na} \mathrm{HPO}_{4}, \mathrm{pH} 7.4$ ) and counted in a hemocytometer.

\section{Lactate Dehydrogenase Release}

Media sampled from control and stretched cells were collected up to $24 \mathrm{~h}$ and lactate dehydrogenase (LDH) release was measured by the assessment of enzyme activity on pyruvate conversion into L-lactate. LDH leakage was expressed as the percentage of total cellular $\mathrm{LDH}$ activity at the end of the experiment. LDH activity was measured in the final cell lysate prepared in $1 \mathrm{M}$ $\mathrm{NaOH}$. LDH activity in the medium plus LDH activity in the cells was taken as total cellular LDH content.

\section{Protein Biosynthesis, Total Protein, AND Total DNA}

To assess the effect of either stretch or ET-1 stimulation on the rate of protein synthesis, cells were pulse-labeled with $0.5 \mu \mathrm{Ci} / \mathrm{mL} \mathrm{L}-\left[4,5-{ }^{3} \mathrm{H}\right]$-leucin over $2 \mathrm{~h}$ before ending the stretch protocol. After termination of the stretch protocol, the cells were washed three times with $10 \%(\mathrm{w} / \mathrm{v})$ trichloric acid (TCA) and lysed in $500 \mu \mathrm{L} 1 \mathrm{M} \mathrm{NaOH}$ for $75 \mathrm{~min}$ at $37^{\circ} \mathrm{C}$. A $250 \mu \mathrm{L}$ fraction was taken and after neutralization with $20 \mu \mathrm{L} 43 \% \mathrm{H}_{3} \mathrm{PO}_{4}, 5 \mathrm{~mL}$ scintillation fluid (Flow Scint IV, Packard, Groningen, The Netherlands) was added and the sample was counted in a $\beta$-counter. Total protein was measured by Bradford assay (14), using bovine serum albumin in $1 \mathrm{M} \mathrm{NaOH}$ as a standard. Total DNA was measured using DAPI as fluorescent DNA indicator as described (15).

\section{Cell Volume and Diameter Analysis BY CASY ${ }^{\circledR}$ 1-SySTEM}

To examine the changes in volume and diameter after stretch or ET-1 stimulation, the cells were washed with phosphate-buffered saline (PBS) and detached from the wells by trypsinization $(0.02 \%$ Trypsin, $0.05 \%$ EDTA in PBS). Per well, cells were collected in $250 \mu \mathrm{L}$ serum-free DMEM/M199 supplemented with DNAse (100 U DNAse $\mathrm{I} / \mathrm{mL}$, Boehringer). A $10-\mu \mathrm{L}$ sample was mixed with $10 \mathrm{~mL}$ isotonic electrolyte (CASYton) and the cell volumes and diameters were measured in the CASY1 
(Schärfe System GmbH, Reutlingen, Germany) using a $60-\mu \mathrm{m}$ nozzle.

\section{MORPHOLOGICAL AND IMMUNOHISTOCHEMICAL Analysis}

To investigate stretch-induced or ET-1-induced morphological changes in cardiomyocytes, cells were cultured at a density of $0.375 \times 10^{5}$ cells $/ \mathrm{cm}^{2}$. After stimulation, the cells were washed with PBS, fixated with $3 \%$ paraformaldehyde for $20 \mathrm{~min}$, and permeabilized for 5 min with $0.2 \%$ Triton X-100. Thereafter, Factin was stained by incubation with FITC-labeled phalloidin for $1 \mathrm{~h}$, and to mark the nucleus, cells were incubated with DNA binding propidium iodide for 10 min. The flexible membranes with the attached stained cardiomyocytes were removed from the culture dishes and mounted into an object tray developed for this purpose. After addition of mounting medium (Vectashield), the cells were covered with a glass coverslip, which was fixated by glueing to the object tray with Three Bond UV Curing Adhesive (Three Bond Europe S.A., Cergy Pontoise Cedex, France). The preparations were analyzed by confocal scanning laser microscopy on a Zeiss LSM (Zeiss, Germany).

\section{PLC- $\beta$ Activity Assay}

To measure ET-1 vs short-term (up to $120 \mathrm{~min}$ ) stretch-induced PLC- $\beta$ activity, the cells were prelabeled with $2 \mu \mathrm{Ci}{ }^{3} \mathrm{H}$-inositol/mL (Amersham) for $24 \mathrm{~h}$. Fifteen minutes before starting the stretch protocol, $10 \mathrm{mM} \mathrm{LiCl}$ was added to the medium containing $130 \mathrm{mM} \mathrm{NaCl}, 4.7$ $\mathrm{mM} \mathrm{KCl}, 1.3 \mathrm{mM} \mathrm{CaCl} 2,0.44 \mathrm{mM} \mathrm{NaH} \mathrm{PO}_{4}, 1.1 \mathrm{mM}$ $\mathrm{MgSO}_{4}, 20 \mathrm{mM} \mathrm{NaHCO}, 11 \mathrm{mM}$ glucose, $20 \mathrm{mM}$ HEPES, pH 7.4 and gassed with $5 \% \mathrm{CO}_{2}$. Then, cells were stretched for 30,60 , or $120 \mathrm{~min}$ or stimulated by $10^{-8} \mathrm{M}$ ET-1 for $30 \mathrm{~min}$. PLC- $\beta$ activity was assessed by measurement of the accumulation of ${ }^{3} \mathrm{H}$-inositol phosphates measured by chromatography on DOWEX 1-X8 as described before (11).

\section{Analysis of PKC Translocation by Western Blotting}

Time dependent translocation responses of PKC in cardiomyocytes were assessed after stretch (up to $2 \mathrm{~h}$ ) or stimulation with PMA $\left(10^{-7} \mathrm{M}, 15 \mathrm{~min}\right)$. Immunoreactivity measurements by Western blotting were carried out as described previously (16). After stimulation cells were lysed and fractionated into a soluble and membrane fractions. Protein fractions were separated by SDS-polyacrylamide gel electrophoresis (PAGE) and electrophoretically transferred to a polyvinylidine fluoride (PVDF) membrane (Boehringer Mannheim $\mathrm{GmbH}$, Germany). Membranes were blocked using TTBS buffer (10 mM Tris/ HCl, pH 7.6, 75 mM NaCl , 0.1\% Tween-
20) supplemented with $0.5 \%$ milk powder and $0.1 \%$ goat serum and incubated with the antibodies against PKC- $\alpha$ or PKC- $\varepsilon(0.2 \mu \mathrm{g} / \mathrm{mL})$ in the same buffer for $16 \mathrm{~h}$ at $4^{\circ} \mathrm{C}$. Antibody binding was detected by the use of ${ }^{125}$ I-labeled $\mathrm{F}\left(\mathrm{ab}^{\prime}\right) 2$ fragments $(100 \mu \mathrm{Ci} / \mathrm{mL}$; dilution 1:1000) or whole $\operatorname{IgG}$ and visualized by a molecular imager (BioRad) and analyzed by Molecular Analyst ${ }^{\circledR}$ Software (BioRad).

\section{MAP KinASE ACTIVATION}

Short-term responses of MAP kinases in cardiomyocytes were assessed by stretching up to $30 \mathrm{~min}$ or stimulating with ET-1 (10 or 20 min). Sodium-ortho-vanadate (0.5 $\mathrm{mM}$ final) was added to the cells simultaneously with the start of exposure to cyclic stretch or ET-1. Lysates were prepared by briefly washing the cells with cold PBS and scraping and shearing in $200 \mu \mathrm{L}$ SDS sample buffer per well (62.5 mM Tris-HCl pH 6.8, 2\% w/v SDS, 10\% glycerol, $50 \mathrm{mM}$ dithiothreitol [DTT], 0.1\% bromophenol blue). Proteins were separated by SDS-PAGE and transferred to a PVDF membrane as described above. Membranes were blocked using TTBS buffer supplemented with $0.5 \%$ milk powder and incubated with the indicated antibodies (dilution 1:2000) for $16 \mathrm{~h}$ at $4^{\circ} \mathrm{C}$. Antibody binding was detected and quantified as described above.

\section{Statistics}

Results are expressed as mean \pm SEM. One-way repeated analysis of variance followed by appropriate post hoc tests (Student-Newman-Keuls method or other as indicated) was used for comparison between groups. Values of $p<0.05$ were considered significant.

\section{RESULTS}

\section{Long-Term Responses of Cyclic Stretch vs ET-1 Rate of Protein Synthesis and Protein/ DNA RATIO}

The cardiomyocytes were stimulated either by cyclic stretch or $10^{-8} \mathrm{M}$ ET- 1 up to $48 \mathrm{~h}$. After $24 \mathrm{~h}$ of stretch, the rate of protein synthesis measured by the incorporation of ${ }^{3} \mathrm{H}$-leucine was increased up to $13 \%$, which is moderate in comparison to the $65 \%$ increase upon ET-1 stimulation (Fig. 1). However, the amount of total protein upon stretch increased with $17 \%$, whereas it was $23 \%$ increased after ET-1 stimulation. Unexpectedly, the total amount of DNA in stretched as well as ET-1-stimulated cardiomyocytes had the tendency to increase as well $(6 \%)$. This very small increase in DNA content likely has caused the protein/DNA ratio to remain constant after stretching, unlike ET-1 stimulation, which causes a significant increase (Fig. 1). 


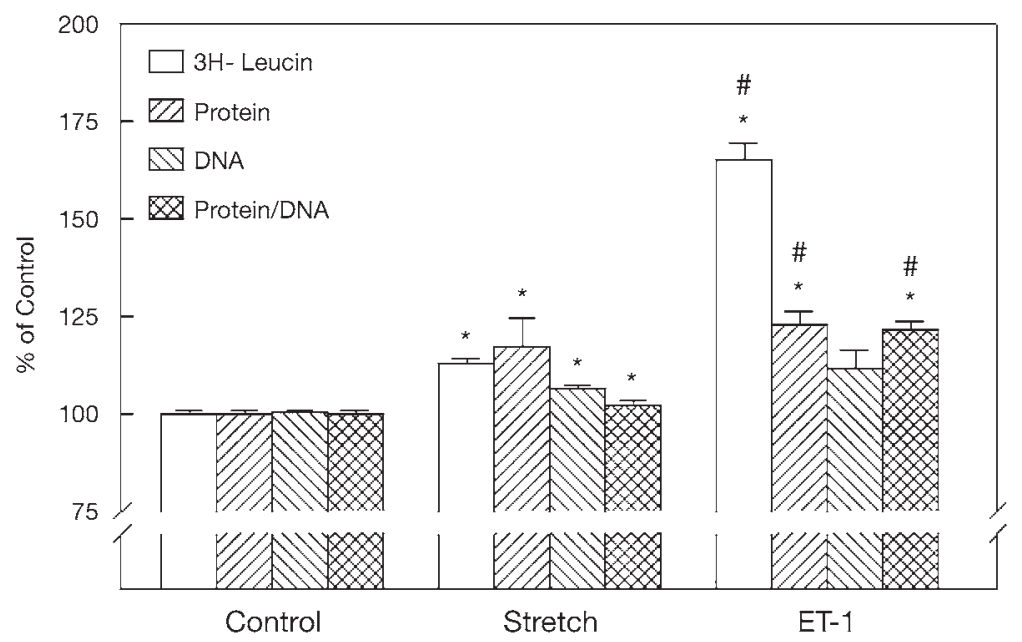

Fig. 1. Effect of cyclic stretch or endothelin (ET)-1 stimulation on protein synthesis, total protein, and total DNA. Cells were either cyclically stretched or stimulated with $10^{-8} \mathrm{M}$ ET-1 for $24 \mathrm{~h}$. Rate of protein synthesis was determined by pulse labeling with L-[4,5-3 H]-leucin. Total protein and DNA was assessed as described in "Materials and Methods." Presented data are expressed as percentage of the control values and represent mean values \pm SEM of 19 experiments. ${ }^{*} p<0.05$ vs control; $\# p<0.05$ vs stretch.

\section{Cell Viability After Cyclical Stretch}

To monitor the condition of the cardiomyocytes during cyclic stretch, we tested for LDH leakage. Slight LDH leakage, expressed as percentage of total cell content, from both control and stretched cells was detected to occur continuously. At the onset of the experiment, LDH leakage was $9.82 \pm 3.08 \%$ and $5.92 \pm 1.65 \%$ of total cellular LDH activity in control and stretched cells, respectively, whereas after $22 \mathrm{~h}$, the leakage from control and stretched cells was $9.93 \pm 1.53 \%$ and $7.49 \pm 1.09 \%$ of total cellular LDH activity, respectively. Therefore, there is no indication of more damage to the cells caused by cyclic stretch. When the cultures were checked for changes in the number of intact cells using the colorimetric MTT assay, even an $11 \%$ higher OD was found in cardiomyocytes that were cyclically stretched for $24 \mathrm{~h}$. This finding may indicate an increase of the number of mitochondria per cardiomyocyte. To exclude an increase in the number of cells, we also detached them from the wells by trypsinisation and counted them in a hemocytometer after $24 \mathrm{~h}$ of stretch. No significant differences were found between the counted number of control and stretched cells (not shown).

\section{Effect of Stretch on Cellular Volume AND Diameter}

To further substantiate the hypertrophic response measured by the rate of protein synthesis and protein/DNA ratio, we analyzed the changes in cellular volume using a system that combines particle measurement technique (resistance measurement) with a contemporary signal processing method (pulse area analysis). Cardiomyocytes that were stretched for 24 or $48 \mathrm{~h}$ were detached from their wells and analyzed for their volume and diameter (Fig. 2). After $24 \mathrm{~h}$ of cyclic stretch, their volume was significantly increased by $14.5 \%$ whereas after $24 \mathrm{~h}$ of ET- 1 stimulation, the cells were enlarged by $18.8 \%$. Furthermore, after $24 \mathrm{~h}$ of cyclic stretch or ET-1 stimulation, the cellular diameter increased significantly by $3.4 \%$ and $6.6 \%$, respectively, in comparison to $24 \mathrm{~h}$ control cells.

\section{Morphological Changes and Cytoskeletal Rearrangements}

Short-term static uni-axial stretch-induced and ET-1induced growth responses of cardiomyocytes have previously been reported to lead to rearrangement or accumulation and assembly of the cytoskeletal actins $(17,18)$. In the present study, we used FITC-labeled phalloidin to tag F-actin structures in the cardiomyocytes and propidium iodide to identify the nuclei. Although the cytoskeletal changes were already observed after 24 $\mathrm{h}$, they were more clearly visible after $48 \mathrm{~h}$ of stretch stimulation (Fig. 3). In the control situation, stained Factin was seen in sarcomeres loosely arranged in the cardiomyocyte. In the cyclically stretched cardiomyocytes, F-actin was particularly seen as (stress-)fibers arranged in all kinds of orientations (compare Fig. 3A,B). Whether F-actin changes implicate only rearrangements or increased protein or both can not be derived from these experiments. In contrast, ET-1 stimulation of the cardiomyocytes revealed a clear rearrangement and accumulation of F-actin in alignment with the sarcomeres and fibers (compare Fig. 3B,C). 


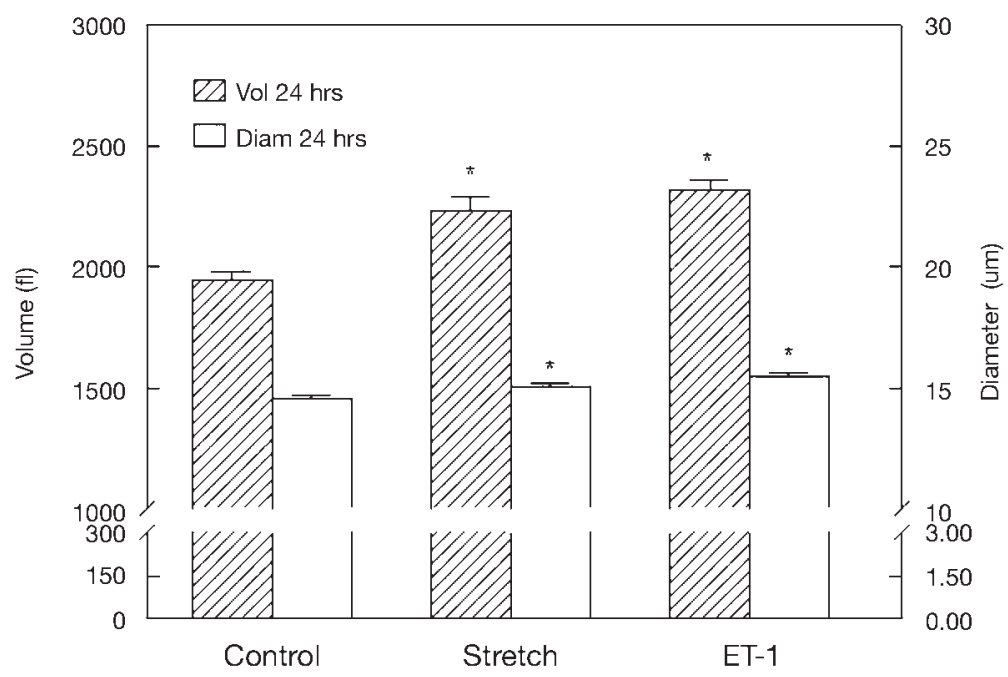

Fig. 2. Cyclical stretch or endothelin (ET)-1-mediated changes in cellular volume or diameter. Cardiomyocytes that were cyclically stretched or stimulated with $10^{-8} \mathrm{M}$ ET- 1 up to $48 \mathrm{~h}$ were detached from their wells and their volume and diameter was analyzed using "CASY ${ }^{\circledR}$ 1-technology" as described in "Materials and Methods." Presented data are expressed as percentage of the control values and represent mean values \pm SEM of five experiments. ${ }^{*} p<0.05$ vs control.
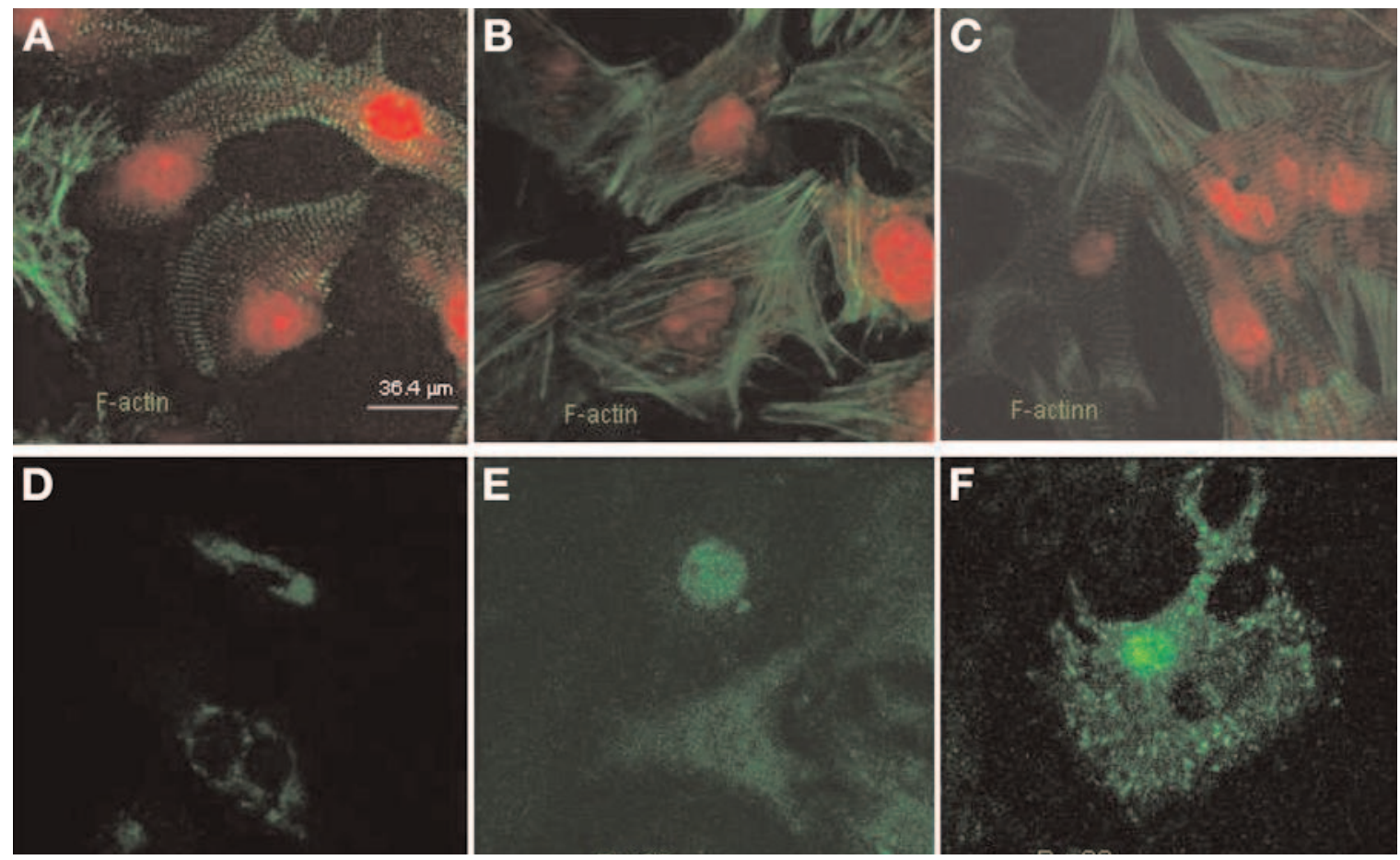

Fig. 3. Cyclical stretch or endothelin (ET)-1-induced long term F-actin rearrangement (A-C) or short-term ET-1 mediated p38 mitogen-activated protein (MAP) kinase phosphorylation responses (D-F) visualized by confocal laser scanning microscopy. A-C: rearrangement of actin structures. Cardiomyocytes were stretched or stimulated with $10^{-8} \mathrm{M}$ ET- 1 for $48 \mathrm{~h}$. Fluorescein isothiocyanate (FITC)-labeled phalloidin and propidium iodide is used to identify the F-actin structures and the nucleus respectively. A, control cells; B, stretched cells; C, ET-1-stimulated cells. D-F: ET-1-mediated translocation of activated p38 protein kinase. Identification by the use of Phospho-specific p38 MAP kinase (Thr180/Thr182) primary antibody, visualization with an FITC-conjugated secondary antibody. D, blanc without primary antibody; E, control; F, 10-8 M ET-1 for 10 min. 


\section{Autocrine Role of ET-1 During Cychical STRETCH}

To exclude a possible paracrine or autocrine involvement of ET-1 in mediating the cyclic stretch-induced response, we tested the effect of a specific $\mathrm{ET}_{\mathrm{A}}$ receptor antagonist $\left(10^{-6} \mathrm{M}\right) \mathrm{BQ} 123$ on the rate of protein synthesis. The presence of BQ123 did not influence the cyclic stretch-induced increase in protein synthesis, expressed as percentage of $24 \mathrm{~h}$ control $(112.0 \pm 1.88 \%$ and $114.4 \pm$ $2.55 \%$, respectively with or without BQ123). As expected, the ET-1 induced increase in protein synthesis $(167.2 \pm 4.83 \%)$ was markedly but not completely inhibited by BQ123 to $126 \pm 4.80 \%$ as compared to control. In another set of experiments, the influence of AT1 and AT2 receptor blockade on the cyclic stretch-mediated response was tested but no effects were found either (data not shown). Moreover, previously, we were unable to detect significant amounts of AngI and Ang II in the conditioned medium over an entire 24 -h period of cyclic stretch (12).

\section{Short-Term Responses of Cyclic Stretch vs ET-1 Activation of PLC- $\beta$ and Translocation OF PKC- $\alpha$ AND $-\varepsilon$}

Up to 30 min of cyclic stretch did not significantly affect the production of total inositol phosphates $\left(\operatorname{InsP}_{n}\right)$, which is the indicator of activation of PLC- $\beta$ (2.77 \pm $0.22 \%$ of cellular $\left[{ }^{3} \mathrm{H}\right]$-inositol as compared to $2.30 \pm$ $0.16 \%$ in the control situation). In contrast, stimulation of the cardiomyocytes with $10^{-8} \mathrm{M}$ ET- 1 for $30 \mathrm{~min}$ did strongly increase $\operatorname{InsP}_{\mathrm{n}}$ accumulation $(16.3 \pm 2.86 \%$ of cellular $\left[{ }^{3} \mathrm{H}\right]$-inositol) as reported before (11). Signaling downstream of PLC- $\beta$ was also studied by monitoring the intracellular translocation of PKC isoenzymes. As assessed by Western blot analysis, in cardiomyocytes that were cyclically stretched up to $120 \mathrm{~min}$, neither PKC- $\alpha$ nor PKC- $\varepsilon$ was detectably translocated to the membrane fraction, which is consistent with the absence of activation of PLC- $\beta$. The membrane-bound PKC- $\alpha$ fraction at 0 min was $11.7 \pm 1.26 \%$ of the total PKC- $\alpha$ fraction and did not change significantly up to $90 \mathrm{~min}$ $(14.5 \pm 1.99 \%)$. For PKC- $\varepsilon$, it was $42.3 \pm 4.21 \%$ at $0 \mathrm{~min}$ and $43.5 \pm 3.00 \%$ after $120 \mathrm{~min}$. As we reported previously, in a similar time range $10^{-8} \mathrm{M}$ ET-1 produced a marked translocation of PKC- $\varepsilon$ from the cytosol to the membrane but had no effect on PKC- $\alpha$ either $(16,19)$.

\section{Activation of MAP Kinases}

We subjected the cardiomyocytes to cyclic stretch up to $30 \mathrm{~min}$ and measured the phosphorylation of several MAP kinase types. When using phospho-specific p42/p44 MAP kinase (ERK1/ERK2) antibody (Fig. 4A), we measured a small increase in phospho-

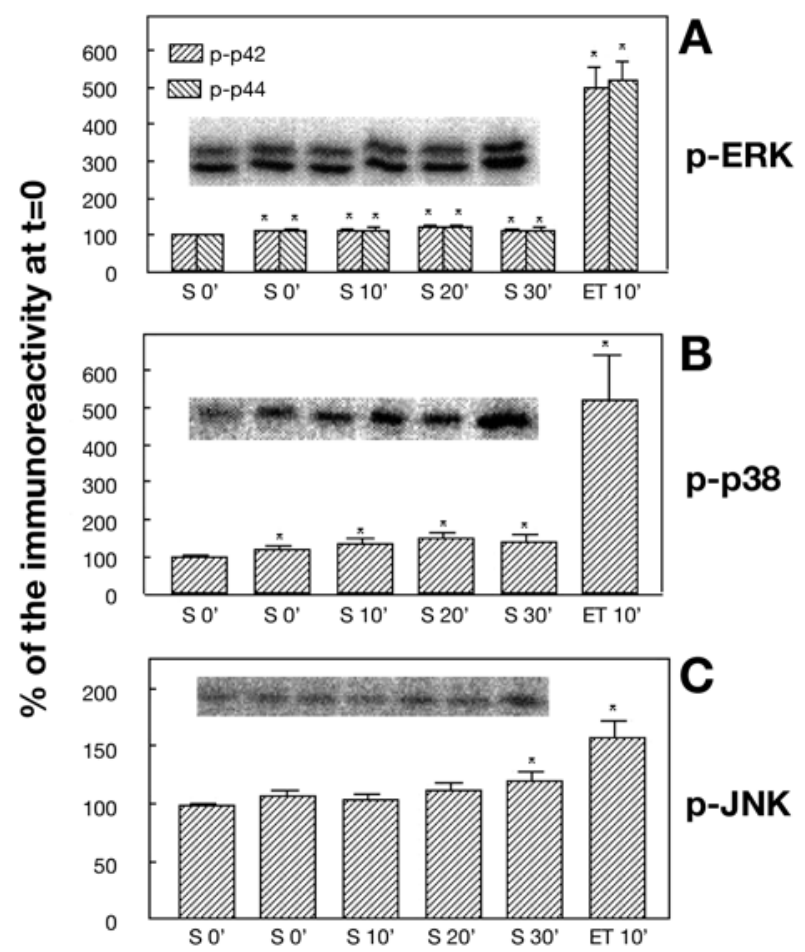

Fig. 4. Cyclic stretch (0-30 min) or ET-1 $\left(10^{-8} M\right.$ for 10 min)-induced time-dependent phospho-p42/p44 protein kinase (ERK1/ERK2) (A), phospho-p38 protein kinase (B), and phospho-JNK (C). The inserted Western blot ${ }^{125} \mathrm{I}-$ images are each representative examples of the corresponding type of mitogen-activated protein kinase phosphorylation. The columns represent means \pm SEM of six to seven experiments. ${ }^{*} p<0.05$ vs immunoreactivity at $0 \mathrm{~min}$.

ERK1/ERK2 reaching at $20 \mathrm{~min}$ a maximum of $121 \pm$ $5.9 \%$ (phospho-ERK1) and $120 \pm 6.6$ (phospho-ERK2) of control. For comparison, stimulation for $10 \mathrm{~min}$ with ET-1 was sufficient to increase the total of phosphorylated ERK1/ERK2 to $501 \pm 54.9 \%$ and $519 \pm 53.7 \%$ of control, respectively. P38 MAP kinase was also activated by cyclic stretch, as we found a transient increase in phosphorylated p38 protein that peaked significantly at $20 \mathrm{~min}$ from onset with $151.4 \%$ of control. Again, stimulation with ET-1 for 10 min resulted in a much stronger activation of p38 MAP kinase of 521 $\pm 119.6 \%$ of control (Fig. 4B). This ET-1-induced response could be also immunohistochemically confirmed, as we observed a positive staining of phosphorylated p38 MAP kinase after 10 min of ET-1 (Fig. 3F). Cyclic stretching of the cardiomyocytes, however, did not increase phosphorylated JNK until $30 \mathrm{~min}$, when p-JNK was $120 \%$ of control, whereas after 10 min ET-1 stimulation, an increase of phosphorylated JNK by $157 \%$ of control was detected (Fig. 4C). 


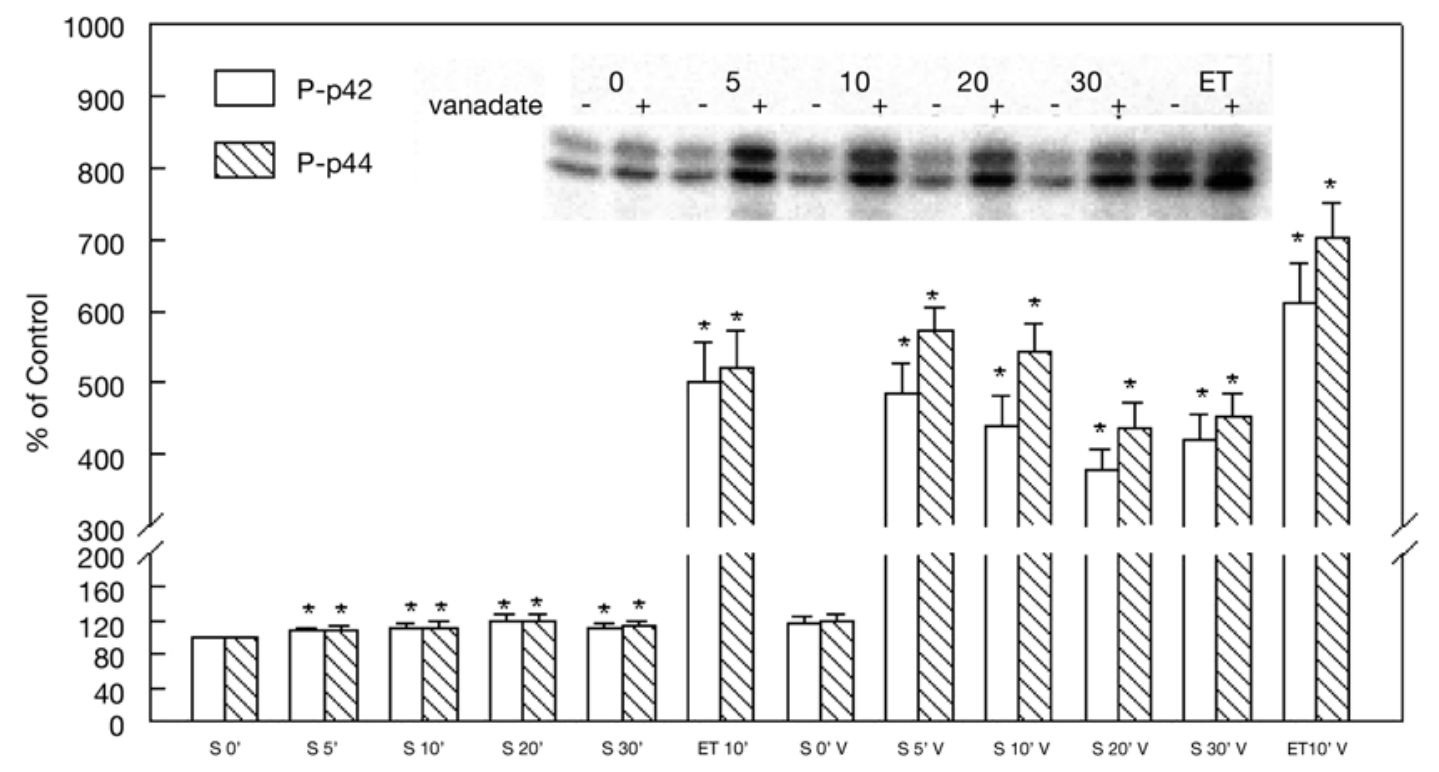

Fig. 5. Cyclical stretch or endothelin (ET)-1 (10-8 $M$ for $10 \mathrm{~min}$ )-induced time dependent phospho-p42/p44 protein kinase (ERK1/ERK2) response with or without tyrosine-P phosphatase inhibitor vanadate. The inserted Western blot ${ }^{125}$ I-image is a representative example. The columns represents means $\pm \mathrm{SEM}^{*} p<0.05 \mathrm{vs}$ immunoreactivity at 0 min.

Phosphorylation of MAP kinases requires the activation of MAP kinase kinase, which has been demonstrated to be the consequence of protein tyrosine phosphorylation. The minor responses of ERK1/ERK2 and p38 MAP kinases after cyclic stretch prompted us to test the effect of the presence of a tyrosine phosphatase inhibitor vanadate. Indeed, the presence of $0.5 \mathrm{mM}$ sodium-ortho-vanadate during stretch stimulation dramatically enhanced the quantity of phosphorylated ERK1/ERK2 (Fig. 5) and p38 MAP kinases (not shown). Already at $5 \mathrm{~min}$ of stretch, we detected a $385 \pm 42.0 \%$ and $471 \pm 32.0 \%$ increase compared to baseline, phosphorylated ERK1 and ERK2, respectively. These high levels of phosphorylated ERK1 and ERK2 continued up to $30 \mathrm{~min}$ of stretch. Likewise, stimulation of the cardiomyocytes with ET-1 in the presence of sodium-orthovanadate increased the quantity of phosphorylated ERK1 and ERK2 further to $610 \pm 57.1 \%$ and $703 \pm 47.4 \%$. Again, already at $5 \mathrm{~min}$, we found phosphorylated p38 MAP kinase levels of $602 \pm 146.1 \%$, which percentage increased in time up to $1023 \pm 70.2 \%$ after $30 \mathrm{~min}$. Vanadate, however, had only a small effect on phosphoJNK levels during stretch as well as during ET-1 stimulation (data not shown).

\section{Effects of Tyrosine Kinase or PI3 Kinase-AkT Inhibition on Cyclic Stretch-Induced LONG-TERM RESPONSES}

To further substantiate whether tyrosine kinases are involved in the transduction of the cyclic stretch- induced signal, we studied the effect of the nonselective inhibitor Genistein on the rate of protein synthesis, protein content, DNA content, and protein/DNA ratio. Addition of Genistein $(50 \mu M) 2 \mathrm{~h}$ before the start of the cyclic stretch protocol caused a significant reduction of protein synthesis rate and total protein content after 24 $\mathrm{h}$ of cyclic stretch (Fig. 6). However, the addition of Genistein to $24 \mathrm{~h}$ control incubated cardiomyocytes reduced the protein synthesis rate and total protein content to the same extent. Genistein did not affect DNA content in neither control nor cyclically stretched cells. Besides the MAP kinase and tyrosine kinase pathways, the PI-3 kinase-Akt pathway is proposed to be as well part of the mechanotransduction cascade pathway (20). To test this, PI-3 kinase inhibitor Wortmannin was added during cyclic stretching of the cells (Fig. 7). Like the Genistein, $1 \mu M$ Wortmannin did result in an overall reduction of protein synthesis rate and total protein in the stretched as well as control cardiomyocytes, which complicates the interpretation of these inhibitor results.

\section{DISCUSSION}

In this study, we have shown that long-term cyclic stretch induces hypertrophic growth in the model of a primary culture of cardiomyocytes as indicated by increases of the rate of protein synthesis and cell volume and diameter, although these growth parameters responded less markedly in comparison to the effect of ET-1 $\left(10^{-8} M\right)$. Interestingly, compared to ET-1 the effects 


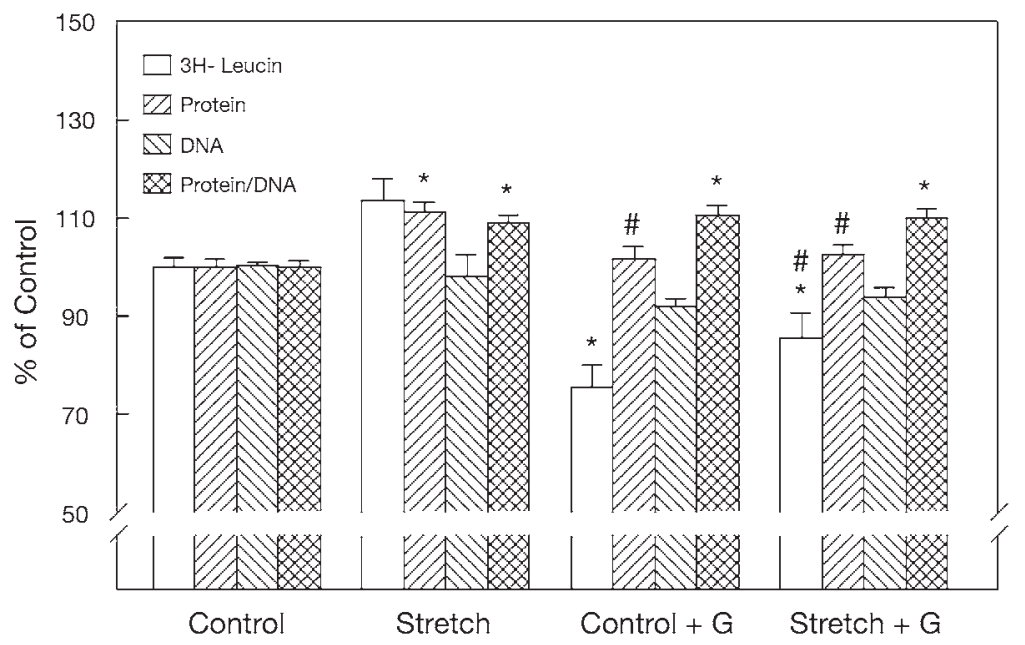

Fig. 6. Effect of tyrosine kinase inhibitor Genistein $(50 \mu M)$ on response of protein synthesis, total protein and total DNA induced by $24 \mathrm{~h}$ of cyclical stretch. Presented data are expressed as percentage of the control values and represent mean values \pm SEM of four experiments. ${ }^{*} p<0.05$ vs control; $\# p<0.05$ vs stretch.

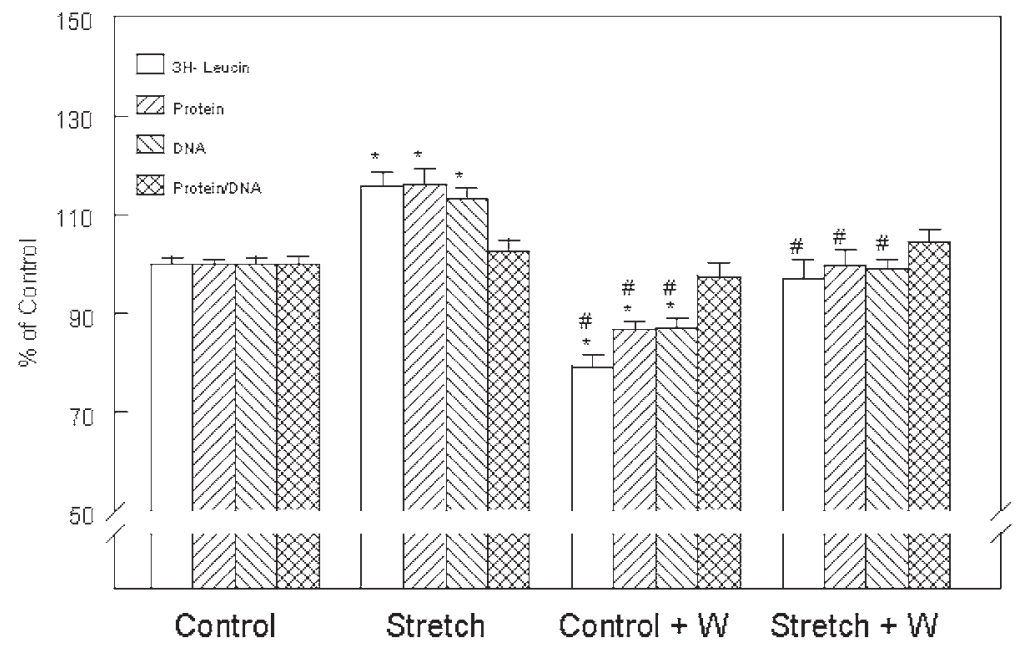

Fig. 7. Effect of PI-3 kinase inhibitor Wortmannin $(1 \mu M)$ on response of protein synthesis, total protein and total DNA induced by $24 \mathrm{~h}$ of cyclical stretch. Presented data are expressed as percentage of the control values and represent mean values \pm SEM of five experiments. * $p<0.05$ vs control; $\# p<0.05$ vs stretch.

of cyclic stretch, stimulation on the intracellular localization of the F-actin rearrangements differ considerably. Likewise, the short-term signaling responses of cyclic stretch vs ET- 1 at the level of PLC- $\beta$ and PKC- $\varepsilon$ are different. On the other hand, cyclic stretch and, to a greater extent ET-1, significantly stimulate downstream signaling through ERK, p38 MAP kinase, and JNK pathways, whereas involvement of tyrosine kinase and PI-3 kinaseAkt signaling in the cyclic stretch-induced growth response could not be proven using specific inhibitors.

In the majority of earlier studies on the signaling processes involved in the mechanically induced hyper- trophic responses, short-term static uni-axial stretch was applied to cultured neonatal cardiomyocytes $(8,21)$. Because the intact (pressure or volume overloaded) heart in situ contracts rhythmically, prolonged in vitro exposure of cardiomyocytes to cyclic stretch better mimics the in vivo (patho)physiology. Therefore, it is not a surprising finding that $24 \mathrm{~h}$ of cyclic stretch, like short-term static uni-axial stretch, induces increased protein synthesis, cell volume and diameter, and the morphological changes characteristic of hypertrophic growth. Moreover, our data confirm that short-term cyclic stretch induces activation of ERK1/ERK2, p38 
MAP kinase, and c-JNK $(8,22)$. However, unlike previous reports on the common activation of signaling pathways by short-term uni-axial static stretch and ET-1 $(23,24)$ stimulation, we observe also different responses. First, the upstream part of signaling by cyclic stretch does not follow the PLC $\beta$-PKC cascade, which, however, is markedly activated during ET-1 stimulation. On the other hand, it should be noticed that Ruwhof et al. (25) found twofold stimulation PLC- $\beta$ stimulation due to exposure to cyclic stretch. Nonetheless, this stimulation is still much less pronounced compared to the ET-1 stimulation (about sevenfold). Second, only in the presence of the protein-tyrosine phosphatase inhibitor does vanadate cyclic stretch induce a very strong MAP kinase response, which is almost similar to the response induced by ET-1. Third, during cyclic stretch, we observed F-actin particularly as (stress-) fibers arranged in all kinds of orientations whereas during ET-1 stimulation, F-actins rearranged and accumulated clearly within the region of the sarcomeres and fibers.

In order to directly compare cyclic stretch and ET-1 with respect to signaling and the hypertrophic growth responses, we examined also several well known growth parameters (protein synthesis, protein/DNA ratio, cellular volume and diameter, and rearrangements of cytoskeletal actin) besides the key steps of activation of potentially involved signaling cascades (PLC- $\beta$, PKCs, MAP kinases, etc.). Most of the previous reports on static uni- or biaxial stretch-induced responses of cardiomyocytes were focused on only a limited number of parameters of hypertrophy and a selected number of signaling pathways $(17,18,26,27)$. Moreover, none of these reports made a direct comparison between stretch- and neurohumoral factor-mediated responses. In some cases, the early gene response or the upregulation of ANF was measured as the only parameter of hypertrophy. For example, it was shown that static uni-axial stretch of cardiomyocytes causes increased expression of the immediate early gene c-fos, which precedes the stimulation of de novo protein synthesis (6), and this may not be required for development of cardiac hypertrophy (28).

Both cyclic stretch and ET-1 stimulation cause an increase of total protein in parallel with an increase in cellular volume and diameter. Dissimilarities, however, were seen in the rate of protein synthesis, as ET-1 stimulates this process much more strongly than cyclic stretch. Unexpectedly, cyclic stretch increased total DNA whereas ET-1 showed only a tendency to increase DNA content. Neonatal myocytes have lost their capacity to divide, but postnatal DNA synthesis has been described to occur in myocyte nuclei of the mouse heart including binucleation (29) or fibroblast proliferation. Stretching cardiomyocytes in vitro may result in the proliferation of this subpopulation of cells, resulting in the relative increase of DNA content. The differences between cyclic stretch- and ET-1-mediated increase in protein synthesis may parallel our findings on the morphology of the cells, i.e., distinct accumulation and rearrangement of F-actin structures. After $48 \mathrm{~h}$ of cyclic stretch, F-actin was seen as fibers orientated in all directions, whereas in ET-1-stimulated cells, a rearrangement as well as an accumulation of F-actin around and aligned with the sarcomeres was seen. It is, however, difficult to extrapolate these findings to the measured differences in increase in total protein and rate of protein synthesis during stretch vs ET-1 stimulation. It should also be noted that, as expected, we did not observe any particular orientation of the myocytes due to circular stretch unlike Kada et al. (30), who applied pulsatile but linear stretch on cultured embryonic rat cardiomyocytes, showing the formation of rod shaped cardiomyocytes that aligned perpendicular to the stretch direction.

In our study, we can exclude the involvement of transient PLC- $\beta$ activation and PKC- $\alpha$ or PKC- $\varepsilon$ translocation in the cyclic stretch-mediated hypertrophic response, although we and many other investigators have convincingly demonstrated their involvement in the ET-1 mediated hypertrophic response $(1,11,19,31)$. Our data obtained with the cyclic stretch are consistent with our observation that an $\mathrm{ET}_{\mathrm{A}}$ blocker did not affect the cyclical stretch-induced increase in protein synthesis. In the static uni-axial stretch model, however, the involvement of autocrine or paracrine formation of Ang II and or ET-1 was shown to occur (6,32). Although Ang II was found to be secreted by statically stretched neonatal rat cardiomyocytes $(33,34)$, and activated Raf1 and MAP kinase could partly be inhibited by specific inhibitors of the $\mathrm{AT}_{1}$ receptor (TCV116) or $\mathrm{AT}_{2}$ receptor (PD123319) $(6,21)$, in our model of cyclic stretch, we could exclude the involvement of these mediators by using the $\mathrm{ET}_{\mathrm{A}}$-receptor antagonist $\mathrm{BQ} 123$ and $\mathrm{AT}_{1}$ and $\mathrm{AT}_{2}$ receptor blockade. Moreover, earlier we demonstrated that the Ang I and Ang II levels measured in medium of control cells and in conditioned medium of cyclic stretched cells were close to the detection limit and that these concentrations decreased to undetectable levels during prolongation of the experiment (12). Antagonists for $\mathrm{ET}_{\mathrm{B}}$ were not tested. There remains a possibility that in addition to ET-1, ET is released by cyclic stretch, which is shown to induce hypertrophy via $\mathrm{ET}_{\mathrm{B}}$ receptors in cardiomyocytes (31).

In the present study, we have assessed for the first time by direct comparison the concerted activation of key signaling pathways in cardiomyocytes that are stimulated by cyclic stretch and by ET-1. Upon cyclic stretch, phosphorylated ERK1/ERK2 as well as phos- 
pho-p38 MAP kinase were found to be slightly increased already after $5 \mathrm{~min}$, whereas phospho-JNK became significantly elevated only after $30 \mathrm{~min}$. In contrast, all MAP kinases including JNK were markedly activated after 10-20 min stimulation with ET-1, although the ET-1-mediated stimulation of JNK was only minor. Addition of the protein-tyrosine phosphatase inhibitor sodium-ortho-vanadate dramatically increased the stretch-mediated responses of phosphorylation of ERK1/ERK2 and p38 MAP kinase to levels comparable to those observed after stimulation with ET1 only. On the other hand, the cyclic stretch- and ET-1mediated phosphorylation of JNK was hardly affected by the addition of protein-phosphotyrosine phosphatase inhibitor. In the translation of the stretch stimulus into a hypertrophic response, both the MAPK pathway and the JAK/STAT are proposed to be active $(9,23)$, but the involved signaling processes upstream of these kinases remain to be clarified. MAP kinases are serine/threonine kinases that become activated upon dual phosphorylation on a tyrosine and a threonine residue. Therefore, vanadate may increase the extent of MAP kinase activation by blockade of tyrosinephosphate dephosphorylation, which was responsible for this MAP kinase activation. Vanadate can exert its effects on MAP kinase activation also by blockade of tyrosine-phosphate dephosphorylation occurring more upstream. The integrin-linked signaling pathway comprises the tyrosine phosphorylation of the focal adhesion kinase (FAK) and Src, which in turn conveys the signal to other signal-transducing molecules such as Grb2, Sos, and PI-3 kinase, linking FAK via Ras and Raf to the MAP kinases $(8,23,35)$. This latter signaling pathway is likely involved in the mediation of cyclic stretch-induced hypertrophic response, which could also be the explanation of the marked effect of vanadate on the cyclic stretch-induced MAP kinase activation. Thus, the observation that, in the absence of vanadate, ET-1 stimulation maximally activates ERK1/ERK2 and p38 MAP kinases whereas upon cyclic stretch, these kinases are only slightly activated, indicates the concurrent activation of protein tyrosine phosphatases during cyclic stretch but not during ET1 stimulation. On the other hand, our observations of lack of PLC- $\beta$ activation and lack of PKC- $\varepsilon$ translocation responses during cyclic stretch are consistent with the hypothesis that cyclic stretch activates MAP kinases through the integrin-linked signaling pathways. Concurrent activation of protein-tyrosine phosphatases may partially block downstream signaling via MAP kinase and, therefore, the JAK/STAT pathway may be preferred.

In conclusion, in this study, we have comparatively assessed the hypertrophic responses of cyclic stretch vs
ET-1 on cardiomyocytes in biochemical terms (protein synthesis, total protein, and DNA), in morphological terms (volume/diameter, changes in actin structures), and by measurement of the activation of key steps in intracellular signaling (activation of PLC- $\beta$, PKC and MAP kinases). Minor differences in responses of cardiomyocytes to stretch or ET-1 were found in biochemical and morphological points of view. However, major differences in the signaling responses were found, which may indicate that cyclic stretch mediates its hypertrophic response mainly through integrin-linked pathways with concurrent activation protein-tyrosine phosphatases.

\section{ACKNOWLEDGMENTS}

This study was supported in part by the Netherlands Heart Foundation (Research Grant \# 97.221).

\section{REFERENCES}

1. Sugden, P. H. (1999) Signaling in myocardial hypertrophy: life after calcineurin? Circ. Res. 84, 633-46.

2. Shubeita, H. E., McDonough, P. M., Harris, A.N., et al. (1990) Endothelin induction of inositol phospholipid hydrolysis, sarcomere assembly, and cardiac gene expression in ventricular myocytes. A paracrine mechanism for myocardial cell hypertrophy. J. Biol. Chem. 265, 20,55520,562.

3. Ng, D. C., Long, C. S., and Bogoyevitch, M. A. (2001) A role for the extracellular signal-regulated kinase and p38 mitogen-activated protein kinases in interleukin-1 beta-stimulated delayed signal tranducer and activator of transcription 3 activation, atrial natriuretic factor expression, and cardiac myocyte morphology. J. Biol. Chem. 276, 29,490-29,498.

4. Nakagami, H., Takemoto, M., and Liao, J. K. (2003) NADPH oxidase-derived superoxide anion mediates angiotensin II-induced cardiac hypertrophy. J. Mol. Cell Cardiol. 35, 851-859.

5. Wollert, K. C., Taga, T., Saito, M., et al. (1996) Cardiotrophin-1 activates a distinct form of cardiac muscle cell hypertrophy. Assembly of sarcomeric units in series VIA gp130/leukemia inhibitory factor receptor-dependent pathways. J. Biol. Chem. 271, 9535-9545.

6. Yamazaki, T., Komuro, I., and Yazaki, Y. (1995) Molecular mechanism of cardiac cellular hypertrophy by mechanical stress. J. Mol. Cell Cardiol. 27, 133-140.

7. Aikawa, R., Nagai, T., Kudoh, S., et al. (2002) Integrins play a critical role in mechanical stress-induced p38 MAPK activation. Hypertension 39, 233-238.

8. Sadoshima, J. and Izumo, S. (1997) The cellular and molecular response of cardiac myocytes to mechanical stress. Annu. Rev. Physiol. 59, 551-571.

9. Pan, J., Fukuda, K., Saito, M., Matsuzaki, J., et al. (1999) Mechanical stretch activates the JAK/STAT pathway in rat cardiomyocytes. Circ. Res. 84, 1127-1136. 
10. Carver, W., Nagpal, M. L., Nachtigal, M., Borg, T. K. and Terracio, L. (1991) Collagen expression in mechanically stimulated cardiac fibroblasts. Circ. Res. 69, 116-122.

11. Van Heugten, H. A., Bezstarosti, K., Dekkers, D. H. and Lamers, J. M. (1993) Homologous desensitization of the endothelin-1 receptor mediated phosphoinositide response in cultured neonatal rat cardiomyocytes. J. Mol. Cell Cardiol. $25,41-52$.

12. Van Kesteren, C. A., Saris, J. J., Dekkers, D. H., et al. (1999) Cultured neonatal rat cardiac myocytes and fibroblasts do not synthesize renin or angiotensinogen: evidence for stretch-induced cardiomyocyte hypertrophy independent of angiotensin II. Cardiovasc. Res. 43, 148-156.

13. Hansen, M. B., Nielsen, S. E., and Berg, K. (1989) Re-examination and further development of a precise and rapid dye method for measuring cell growth/cell kill. J. Immunol. Methods 119, 203-210.

14. Bradford, M. M. (1976) A rapid and sensitive method for the quantitation of microgram quantities of protein utilizing the principle of protein-dye binding. Anal. Biochem. 72, 248-254.

15. Lee, G. M., Thornthwaite, J. T., and Rasch, E. M. (1984) Picogram per cell determination of DNA by flow cytofluorometry. Anal. Biochem. 137, 221-226.

16. Lamers, J. M., Eskildsen-Helmond, Y. E., Resink, A. M., et al. (1995) Endothelin-1-induced phospholipase C-beta and $\mathrm{D}$ and protein kinase $\mathrm{C}$ isoenzyme signaling leading to hypertrophy in rat cardiomyocytes. J. Cardiovasc. Pharmacol. 26(Suppl 3), S100-S103.

17. Sadoshima, J., Takahashi, T., Jahn, L., and Izumo, S. (1992) Roles of mechano-sensitive ion channels, cytoskeleton, and contractile activity in stretch-induced immediate-early gene expression and hypertrophy of cardiac myocytes. Proc. Natl. Acad. Sci. USA 89, 9905-9909.

18. Sadoshima, J., Jahn, L., Takahashi, T., Kulik, T. J., and Izumo, S. (1992) Molecular characterization of the stretchinduced adaptation of cultured cardiac cells. An in vitro model of load-induced cardiac hypertrophy. J. Biol. Chem. 267, 10,551-10,560.

19. Eskildsen-Helmond, Y. E., Bezstarosti, K., Dekkers, D. H., van Heugten, H. A., and Lamers, J. M. (1997) Cross-talk between receptor-mediated phospholipase C-beta and D via protein kinase $C$ as intracellular signal possibly leading to hypertrophy in serum-free cultured cardiomyocytes. J. Mol. Cell Cardiol. 29, 2545-2559.

20. Katsumi, A., Orr, A. W., Tzima, E., and Schwartz, M. A. (2004) Integrins in mechanotransduction. J. Biol. Chem. 279, $12,001-12,004$.

21. Yamazaki, T., Komuro, I., Kudoh, S., et al. (1995) Angiotensin II partly mediates mechanical stress-induced cardiac hypertrophy. Circ. Res. 77, 258-265.

22. Seko, Y., Takahashi, N., Tobe, K., Kadowaki, T., and Yazaki, Y. (1999) Pulsatile stretch activates mitogen-activated pro- tein kinase (MAPK) family members and focal adhesion kinase (p125(FAK)) in cultured rat cardiac myocytes. Biochem. Biophys. Res. Commun. 259, 8-14.

23. Ruwhof, C. and van der Laarse, A. (2000) Mechanical stress-induced cardiac hypertrophy: mechanisms and signal transduction pathways. Cardiovasc. Res. 47, 23-37.

24. Sugden, P. H. and Clerk, A. (1998) "Stress-responsive" mitogen-activated protein kinases (c-Jun N-terminal kinases and p38 mitogen-activated protein kinases) in the myocardium. Circ. Res. 83, 345-352.

25. Ruwhof, C., van Wamel, J. E. T., Noordzij, L. A. W., Aydin, S., Harper, J. C. R. and van der Laarse, A. (2001) Mechanical stress stimulates phospholipase $C$ activity and intracellular calcium ion levels in neonatal rat cardiomyocytes. Cell Calcium 29, 73-83

26. Katsumi, A., Naoe, T., Matsushita, T., Kaibuchi, K., and Schwartz, M. A. (2005) Integrin activation and matrix binding mediate cellular responses to mechanical stretch. J. Biol. Chem. 280, 16,546-16,549.

27. Yazaki, Y., Komuro, I., Yamazaki, T., et al. (1993) Role of protein kinase system in the signal transduction of stretchmediated protooncogene expression and hypertrophy of cardiac myocytes. Mol. Cell Biochem. 119, 11-16.

28. Sadoshima, J. and Izumo, S. (1993) Mechanical stretch rapidly activates multiple signal transduction pathways in cardiac myocytes: potential involvement of an autocrine/ paracrine mechanism. EMBO J. 12, 1681-1692.

29. Anversa, P. and Kajstura, J. (1998) Ventricular myocytes are not terminally differentiated in the adult mammalian heart. Circ. Res. 83, 1-14.

30. Kada, K., Yasui, K., Naruse, K., Kamiya, K., Kodama, I., and Toyama, J. (1999) Orientation change of cardiocytes induced by cyclic stretch stimulation: time dependency and involvement of protein kinases. J. Mol. Cell Cardiol. 31, 247-259.

31. Cullen, J. P., Bell, D., Kelso, E. J., and McDermott, B. J. (2001) Use of A-192621 to provide evidence for involvement of endothelin ET(B)-receptors in endothelin-1-mediated cardiomyocyte hypertrophy. Eur. J. Pharmacol. 417, 157-168.

32. Ito, H., Hirata, Y., Adachi, S., et al. (1993) Endothelin-1 is an autocrine/paracrine factor in the mechanism of angiotensin II-induced hypertrophy in cultured rat cardiomyocytes. J. Clin. Invest. 92, 398-403.

33. Yamazaki, T., Komuro, I., and Yazaki, Y. (1999) Role of the renin-angiotensin system in cardiac hypertrophy. Am. J. Cardiol. 83, 53H-57H.

34. Sadoshima, J., Xu, Y., Slayter, H. S., and Izumo, S. (1993) Autocrine release of angiotensin II mediates stretchinduced hypertrophy of cardiac myocytes in vitro. Cell 75, 977-984.

35. Laser, M., Willey, C. D., Jiang, W., et al. (2000) Integrin activation and focal complex formation in cardiac hypertrophy. J. Biol. Chem. 275, 35,624-35,630. 